\title{
Genetic Variability, Heritability and Genetic Advance for the Phenotypic Traits in Sesame (Sesamum indicum L.) Populations from Ethiopia
}

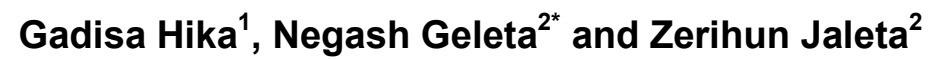 \\ ${ }^{1}$ Arjo Preparatory School, P.O. Box: 10, Arjo, East wollega, Ethiopia \\ ${ }^{2}$ Department of Plant Sciences, College of Agriculture and Natural Resources, Wollega University, \\ P.O Box: 395, Nekemte, Ethiopia
}

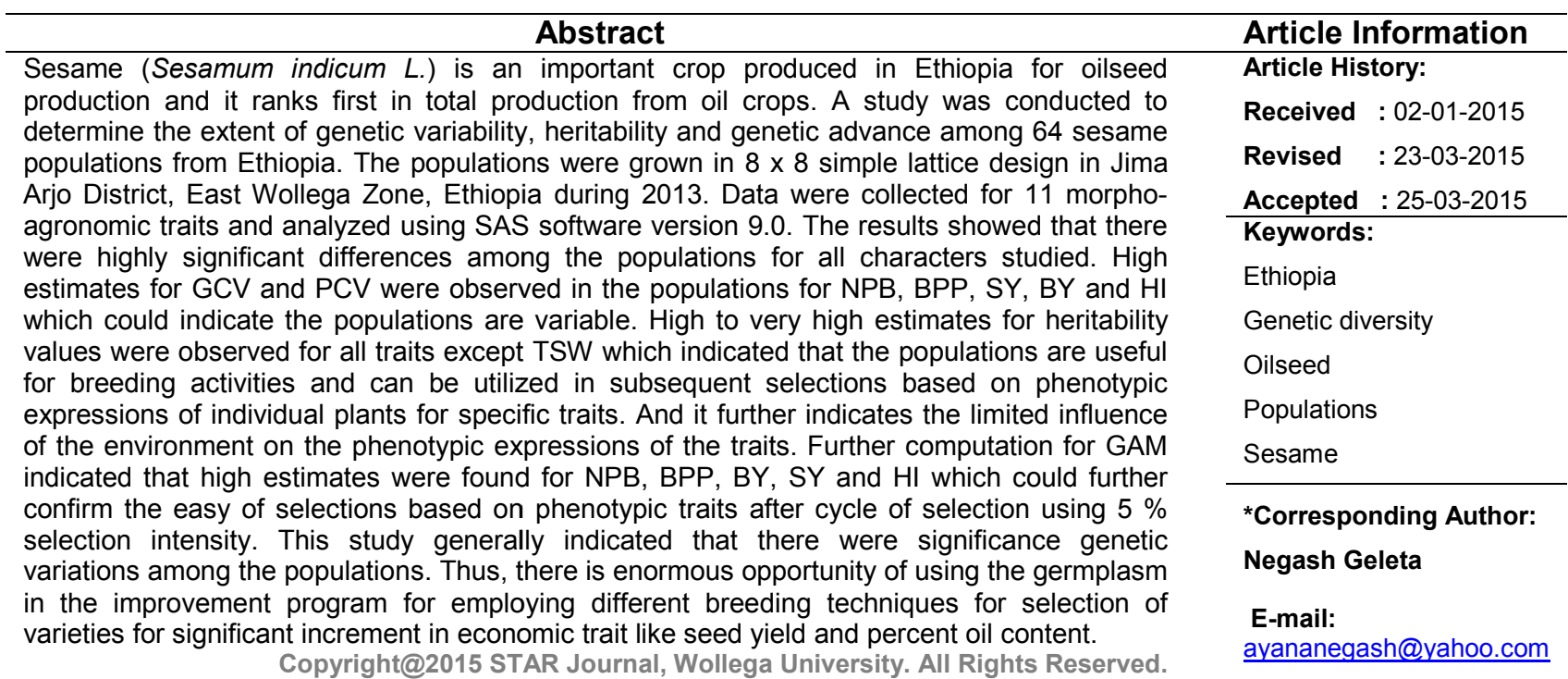

\section{INTRODUCTION}

Sesame (Sesamum indicum L.) is a diploid with $2 n=2 X=26$ chromosomes; a self pollinated crop which belongs to the family of pedaliaceae. Though its origin is believed to be in Indian subcontinent (Bedigian and Harlan, 1986); it has high genetic diversity in east Africa, Ethiopia. The presence of weedy or wild forms of sesame (S. alatum; $2 n=26$ and $S$. latifolium, $2 n=32$ ) in Ethiopia shows that it is indigenous to this country. Sesame production was recorded in the Middle East and India during 3050-3500 BC (Bedigian and Harlan, 1986). Currently, about $60 \%$ of the world's sesame production is from Myanmar, India, China, Ethiopia and Nigeria during 2011 (http://www.factfish.com/statistic/sesame\%20seed,\% 20 production\%20quantity); and Ethiopia is among the top 5 world's producers of sesame seed, linseed and also an important producer of Niger seed (Wijnands et al., 2007; http://www.epospeaeth.org/index.php/ethiopian-sesameand-oilseeds: accessed date December 14/2013). Sesame ranks first in total area and production from oil crops during 2013 in Ethiopia. The total area, production and productivity were 0.299 million ha, 0.220 million tonnes and $0.735 \mathrm{t} \mathrm{ha}^{-1}$, respectively (CSA, 2014). It is a small farmer's crop in the developing countries and it is majorly grown in the small plots (Gulhan et al., 2004). In Ethiopia, the production of sesame is both by small and large scale farmers; and it is an important export commodity. Due to its importance the area coverage and production has increased in the last consecutive years in Ethiopia. In spite of the growing demand for sesame seeds and oil in Ethiopia, the productivity, production and oil extractions methods are traditional.

The production of sesame is for oil and margarines. It is often called the 'queen of oil crops'. Sesame seeds are used whole or processed to produce oil and meal while in Africa the seeds are made into porridges and soups (Gooding et al., 2000). The quality of oil is determined by the fatty acid compositions of the total oil. Its oil is used for salad and cooking dishes. Sesame seed is used for confectionery purpose and an important source of edible oil and is also widely used as a spice. In addition, it is used for pharmaceutical and skin care products and as a synergist for insecticides (Salunkhe and Desai, 1986). The seed contains 50 to $60 \%$ oil which has excellent stability due to the presence of natural antioxidants such as sesamolin, sesamin and sesamol (Brar and Ahuja, 


\section{Gadisa Hika et al.,}

1979).The fatty acid composition of sesame oil varies considerably among the different cultivars worldwide (Yermanos et al., 1972).

Genetic diversity studies were done by different researchers for Ethiopian sesame collections in different times (Endale and Parzies, 2011; Alemu et al., 2013 Desawi et al., 2014, Hika et al., 2014) and the researchers reported that phenotypical and genetic variations have been detected in the specific populations studied. Endale and Parzies (2011) studied 50 populations of Ethiopian sesame using SSR markers and ample amount of genetic variations were reported. Alemu et al. (2013) reported that significant genetic variation were detected using ISSR markers among six farmers' varieties of sesame from Northern Ethiopia indicating that Ethiopia has ample genetic resources of sesame which could be utilized for improvement programs. Knowledge on the extent and pattern of genetic variability present in a specific breeding population is absolutely essential for further improvement of the crop. Besides, knowledge of the naturally occurring diversity in a population helps to identify diverse groups of populations that can be useful for the breeding program. Sesame breeding programs started before three decades in Ethiopia and so far 18 varieties were released for different agro-ecologies in the country based on the moisture, temperature and soil requirements, however only three varieties were produced for export purpose (Wijinands et al., 2007; Geremew et al., 2012;) while the others are out of production due to different reasons. Hence the objectives of the study were to determine the magnitude of phenotypic variations for yield and yield related traits in sesame populations; and to estimate broad sense heritability and genetic advance for different traits of sesame populations.

\section{MATERIALS AND METHODS}

\section{Description of Experimental Site}

The experiment was carried out at Jimma Arjo district, Eastern Wollega Zone, Western Ethiopia. The test location, Jimma Arjo district is $378 \mathrm{~km}$ to the west of Addis Ababa, the capital city of Ethiopia. The district is located at an altitudinal ranges from 1200-1816 meters above sea level; and it receives an average annual rainfall that ranges from $824-2616 \mathrm{~mm}$. The average annual temperature ranges from $18-26^{\circ} \mathrm{C}$ (Unpublished data of Jima Arjo Agricultural Office).

\section{Experimental Materials and Design}

The experimental materials consisted of 64 sesame populations which were collected from different parts of the country (Tigray, Amhara, Oromia, Beneshangul Gumuz and others region) and conserved at the Institute of Biodiversity Conservation (IBC) and the population code, region and altitude of original collection sites were reported in Hika et al. (2014). The trial was laid out using $8 \times 8$ simple lattice design. Seeds of each population was sown in rows by hand on a separate plot size of $6.4 \mathrm{~m}^{2}(4$ rows $\times 4 \mathrm{~m}$ row length $\times 40 \mathrm{~cm}$ between rows and $10 \mathrm{~cm}$ between plants within row spacing respectively). Weeding was done as required uniformly.

\section{Data Collection}

The measurements and other protocol for data collections were dome according to sesame crop descriptors (IPGRI, 2004). Data were collected for days to $50 \%$ flowering, days to $90 \%$ maturity, capsule filling
Sci. Technol. Arts Res. J., Jan-March 2015, 4(1): 20-26

period, plant height, number of branches per plant, number of primary branches per plant, number of capsules per plant, thousand seed weight, biomass yield, seed yield and harvest index.

\section{Data Analysis}

Analysis of variance (ANOVA) was done following the procedure for statically computation for Gomez and Gomez (1984) and it was analyzed using Statistical Analysis System (SAS) Computer software program following SAS statement for simple lattice design (SAS, 2002, version 9.0, USA). The phenotypic and genotypic coefficients of variation were estimated according to the method suggested by Burton and de Vane (1953). Broad sense heritability $\left(h^{2}\right)$ expressed as the percentage of the ratio of the genotypic variance $\left(\sigma^{2} g\right)$ to the phenotypic variance $\left(\sigma^{2} p\right)$ was computed as described by Allard (1960). Genetic advance in absolute unit (GA) and percent of the mean (GAM), assuming selection of superior $5 \%$ of the populations was estimated according to the method illustrated by Johnson et al. (1955).

\section{RESULTS}

\section{Analysis of Variance}

The analysis of variance showed that all the studied characters showed highly significant differences $(P<0.01)$ among the tested sesame populations. This indicates the presence of adequate variability which can be exploited through selection for improving specific traits (Table 1).

\section{Mean, Range and Coefficient of Variation}

The mean seed yield was $511 \mathrm{~kg} \mathrm{ha}^{-1}$ and about $40.63 \%$ of the populations gave seed yield above the mean yield. The maximum yield was obtained from populations Acc-215816 (902 kg ha $\left.{ }^{-1}\right)$. Regarding BY and $\mathrm{HI}, 41$ and $70 \%$ respectively of the populations had higher values as compared to the mean. For TSW, $52 \%$ of the population had more than the mean values and the maximum was $2.99 \mathrm{~g}$. About $59 \%$ and $50 \%$ of the populations gave flower and mature late respectively as compared to the mean of the populations. NPB and PH had maximum values of 9.0 and $127 \mathrm{~cm}$ respectively and $36 \%$ and $45 \%$ of the populations respectively had more than the mean values. The 64 populations studied showed wide range of variability for most of the characters (Tables 2, 3 and 4). Mean ranges in the populations were higher (> 20) for DF, DM, PH, CPP, BY, and SY, while medium mean ranges (10 to 20 ) were observed for BPP and CFP. However, the mean ranges were low $(<10)$ for TSW and NPB. There was high coefficient of variation in the characters for NPB and BPP.

\section{Estimates of Genetic Parameters}

Number of primary branches per plant, the number of branches per plant, seed yield, harvest index and biomass yield had high values (>18\%) of genotypic and phenotypic coefficients of variation (Table 5). Estimates for genotypic and phenotypic coefficients of variation were low $(<18 \%)$ for days to $50 \%$ flowering, days to $90 \%$ maturity, capsule filling period, plant height, and thousand seed weight. The high GCV value of characters suggest that the possibility of improving these trait through selection. The difference between GCV and PCV values was low for days to $50 \%$ flowering, days to $90 \%$ maturity and thousand seed weight; suggesting minimal influence of environment on the expression of the characters so that it is easy to select based on the phenotypes. Heritability in broad sense was greater than $80 \%$ for all traits except for 
Table 1: Mean square values for different morpho-agronomic traits in 64 sesame populations

\begin{tabular}{llccc}
\hline \multicolumn{1}{c}{ Traits } & $\begin{array}{c}\text { Replication } \\
\text { (Df=1) }\end{array}$ & $\begin{array}{c}\text { Blocks with in } \\
\text { rep (adj) } \\
\text { (Df=14) }\end{array}$ & $\begin{array}{c}\text { Populations } \\
\text { (unadj.) } \\
\text { (Df=63) }\end{array}$ & $\begin{array}{c}\text { Intra block } \\
\text { error } \\
\text { (Df=49) }\end{array}$ \\
\hline Days to 50 \% flowering & 3.13 & 1.03 & $59.38^{* *}$ & 1.37 \\
Days to 95 \% maturity & 1.76 & 2.02 & $98.93^{\star *}$ & 2.28 \\
Capsules filling period & 1.13 & 1.36 & $29.69^{\star *}$ & 1.49 \\
Primary branches per plant & 0.07 & 0.13 & $3.74^{* *}$ & 0.175 \\
Number of branches per plant & 5.69 & 0.24 & $4.97^{* *}$ & 0.34 \\
Plant height, cm & 4.5 & 2.61 & $146.88^{* *}$ & 2.71 \\
Number of capsules per plant & 15.82 & 10.48 & $198.25^{\star *}$ & 7.31 \\
Biological yield (kg ha ${ }^{-1}$ ) & 208334.34 & 47807.07 & $867461.23^{* *}$ & 48057.15 \\
Seed yield (kg ha ${ }^{-1}$ ) & 21.72 & 9.81 & $18794.57^{* *}$ & 17.07 \\
Harvest index & 0.002 & 0.00 & $0.005^{\star *}$ & 0.00 \\
Thousand seed weight, (g) & 0.001 & 0.061 & $1282.83^{* *}$ & 0.037 \\
\hline
\end{tabular}

$\mathrm{Df}=$ degrees of freedom; ${ }^{* *}$ means significant at $1 \%$ probability level

Table 2: Estimates of mean values, range and coefficient variation for morphological traits in sesame populations

\begin{tabular}{llll}
\hline Characters & Mean & Range & CV (\%) \\
\hline Days to $50 \%$ flowering & 60.48 & $45.0-70.0$ & 1.88 \\
Days to 90 \% maturity & 133.00 & $116.0-146.0$ & 1.12 \\
Plant height, cm & 104.55 & $87.0-127.0$ & 1.57 \\
Capsule filling period & 46.46 & $39-56.0 .0$ & 2.59 \\
Number of primary branches & 2.49 & $1.0-9.0$ & 16.33 \\
Number of branches per plant & 2.97 & $1.0-11.0$ & 17.63 \\
Number of capsules per plant & 90.66 & $68.0-116.0$ & 3.08 \\
Biological yield $\left(\mathrm{kg} \mathrm{ha}^{-1}\right)$ & 2991.00 & $1563.0-3916.0$ & 7.32 \\
Seed yield (kg ha $\left.{ }^{-1}\right)$ & 510.75 & $328.0-625.0$ & 0.77 \\
Harvest index & 0.18 & $0.1-0.31$ & 10.20 \\
Thousand seed yield $(\mathrm{g})$ & 2.40 & $2.0-3.41$ & 4.27 \\
\hline
\end{tabular}

TSW (45.13\%) (Table 5). Estimates of genetic advance as percent of the mean (GAM) were greater than $30 \%$ for $\mathrm{PB}, \mathrm{BPP}, \mathrm{SY}, \mathrm{BY}$ and HI.

\section{DISCUSSION}

The 64 sesame populations were significantly different for the 11 morphological characters studied. The variations could be attributed to the genetic and phenotypic. The genetic components are useful and can be exploited for breeding programs since it can be transferred to the offspring. Different researchers have reported that genetic diversity exists among the Ethiopian sesame collections (Endale and Parzies, 2011; Gidey et al., 2012; Alemu et al., 2013). Hika et al. (2014) previously reported for the same populations for morphological divergence and correlations among seed yield and other traits. And the same authors reported that the 64 populations were grouped or clustered in to 4 major groups and each group had its own characteristics. In the present study phenotypic variations were observed for the 11 studied traits among the 64 sesame populations but the extent of variation varies with the traits. For instance; mean ranges in the populations were higher (> 20) for DF, $\mathrm{DM}, \mathrm{PH}, \mathrm{CPP}, \mathrm{BY}$, and $\mathrm{SY}$, while medium mean ranges (10 to 20) were observed for BPP and CFP. However, the mean ranges were low $(<10)$ for TSW and NPB.

In the present study, the mean seed yield was $511 \mathrm{~kg}$ $\mathrm{ha}^{-1}$ and about $40.63 \%$ of the populations gave seed yield above the mean yield. The maximum yield was obtained from populations Acc-215816 (902 kg ha-1), and this genotype gave the maximum thousand seed weight (2.99 g). The present mean seed yield reported is inferior to the mean seed yield reported by Desawi et al. (2014) for other Ethiopian sesame populations evaluated for seed yield and other agronomic traits. This might be due to environmental variations in addition to the genetic differences that influence the performances of quantitative traits. Desawi et al. (2014) conducted the field experiment in the Northern lowland areas of Ethiopia with low and erratic annual rainfall distribution which varies between $850 \mathrm{~mm}$ and $1140 \mathrm{~mm}$ and mean annual temperature of 28 degree Celsius, while the present study was carried out in western lowlands with humid climate and better rainfall distribution but low annual temperature (Hika et al., 2014) and soil physical and chemical properties differs from the former. The soil physico-chemical characteristic of the latter is majorly acidic in nature and not useful for crop production especially for oil crops like sesame (Deressa, 2013). Number of primary branches per plant, the number of branches per plant, seed yield, harvest index and biomass yield had high values $(>18 \%$ ) of genotypic and phenotypic coefficients of variation. Similar results were reported by other researchers (Gangarde et al., 2009; Deswai et al., 2014) for BPP, CPP, NPB and $S Y$. As yield contributing factor, number of primary braches per plant had significant positive correlation and high direct effect on seed yield (Hika et al., 2014). Hence, the average number of primary branches per plant observed for the present populations was less value that contributed to the low average seed yield. 
Table 3: Mean values of phenologic and vegetative parameters in 64 sesame populations

\begin{tabular}{|c|c|c|c|c|c|c|c|}
\hline No. & Populations & DF & DM & CFP & $\mathrm{PH}$ & PB & BPP \\
\hline 1 & Acc- 249212 & 60 & 125 & 46 & 95 & 3 & 4 \\
\hline 2 & Acc-202289 & 63 & 132 & 43 & 105 & 2 & 2 \\
\hline 3 & Acc-202374 & 67 & 122 & 41 & 111 & 2 & 2 \\
\hline 4 & Acc-202376 & 63 & 120 & 44 & 107 & 2 & 3 \\
\hline 5 & Acc-241305 & 55 & 137 & 51 & 97 & 2 & 2 \\
\hline 6 & Acc-202356 & 61 & 140 & 46 & 118 & 1 & 2 \\
\hline 7 & Acc- 241320 & 58 & 130 & 49 & 101 & 2 & 3 \\
\hline 8 & Acc-202309 & 60 & 132 & 50 & 120 & 2 & 2 \\
\hline 9 & Acc-241301 & 70 & 133 & 46 & 118 & 2 & 3 \\
\hline 10 & Acc-202308 & 69 & 140 & 47 & 108 & 1 & 2 \\
\hline 11 & Acc-241304 & 58 & 136 & 43 & 95 & 2 & 2 \\
\hline 12 & Acc-202312 & 68 & 119 & 47 & 103 & 7 & 8 \\
\hline 13 & Acc-202335 & 63 & 137 & 47 & 93 & 3 & 3 \\
\hline 14 & Acc-202353 & 66 & 145 & 51 & 91 & 2 & 2 \\
\hline 15 & Acc-241300 & 69 & 122 & 39 & 106 & 1 & 1 \\
\hline 16 & Acc-228816 & 59 & 143 & 53 & 110 & 2 & 2 \\
\hline 17 & Acc-202287 & 67 & 136 & 47 & 127 & 2 & 2 \\
\hline 18 & Acc-241328 & 64 & 131 & 49 & 109 & 3 & 3 \\
\hline 19 & Acc-211921 & 63 & 128 & 51 & 101 & 2 & 3 \\
\hline 20 & Acc-202339 & 66 & 136 & 43 & 104 & 2 & 2 \\
\hline 21 & Acc-202329 & 56 & 129 & 47 & 98 & 1 & 2 \\
\hline 22 & Acc-202315 & 53 & 134 & 51 & 116 & 2 & 3 \\
\hline 23 & Acc-203099 & 51 & 131 & 43 & 98 & 2 & 2 \\
\hline 24 & Acc-202320 & 57 & 140 & 47 & 101 & 2 & 3 \\
\hline 25 & Acc-212995 & 49 & 126 & 49 & 105 & 3 & 3 \\
\hline 26 & Acc-202345 & 54 & 141 & 51 & 107 & 2 & 2 \\
\hline 27 & Acc-9242 & 61 & 137 & 43 & 113 & 1 & 2 \\
\hline 28 & Acc-241294 & 52 & 143 & 52 & 104 & 1 & 2 \\
\hline 29 & Acc-202330 & 58 & 141 & 44 & 116 & 1 & 1 \\
\hline 30 & Acc-241297 & 61 & 131 & 51 & 113 & 2 & 2 \\
\hline 31 & Acc-212633 & 47 & 143 & 53 & 98 & 2 & 2 \\
\hline 32 & Acc-215816 & 62 & 146 & 43 & 92 & 9 & 11 \\
\hline 33 & Acc-216896 & 57 & 131 & 47 & 97 & 1 & 2 \\
\hline 34 & Acc-202323 & 61 & 142 & 43 & 96 & 1 & 1 \\
\hline 35 & Acc-202313 & 52 & 125 & 44 & 118 & 2 & 2 \\
\hline 36 & Acc-241298 & 49 & 137 & 51 & 117 & 7 & 9 \\
\hline 37 & Acc-202332 & 63 & 141 & 41 & 104 & 1 & 2 \\
\hline 38 & Acc-202288 & 61 & 123 & 44 & 106 & 2 & 3 \\
\hline 39 & Acc-241296 & 51 & 116 & 41 & 115 & 1 & 2 \\
\hline 40 & Acc-202511 & 60 & 127 & 47 & 121 & 2 & 3 \\
\hline 41 & Acc-202343 & 54 & 123 & 41 & 114 & 2 & 2 \\
\hline 42 & Acc-241293 & 61 & 124 & 46 & 107 & 2 & 2 \\
\hline 43 & Acc-241347 & 61 & 127 & 49 & 98 & 2 & 2 \\
\hline 44 & Acc-203104 & 70 & 145 & 51 & 104 & 3 & 3 \\
\hline 45 & Асc-241299 & 54 & 122 & 43 & 91 & 3 & 3 \\
\hline 46 & Acc-202327 & 61 & 134 & 41 & 104 & 2 & 3 \\
\hline 47 & Acc-241291 & 69 & 140 & 47 & 98 & 3 & 3 \\
\hline 48 & Acc-241314 & 62 & 136 & 51 & 107 & 4 & 5 \\
\hline 49 & Acc-235405 & 59 & 141 & 42 & 104 & 3 & 4 \\
\hline 50 & Acc-202364 & 64 & 126 & 47 & 98 & 3 & 3 \\
\hline 51 & Acc-202306 & 68 & 131 & 39 & 101 & 3 & 3 \\
\hline 52 & Acc-241303 & 64 & 127 & 41 & 98 & 2 & 2 \\
\hline 53 & Acc-202286 & 62 & 131 & 56 & 104 & 3 & 3 \\
\hline 54 & Acc-212994 & 58 & 136 & 43 & 111 & 4 & 4 \\
\hline 55 & Acc-202317 & 61 & 144 & 47 & 93 & 3 & 3 \\
\hline 56 & Acc-202286 & 64 & 134 & 50 & 88 & 2 & 3 \\
\hline 57 & Acc-241329 & 69 & 137 & 49 & 96 & 3 & 3 \\
\hline 58 & Acc-202373 & 63 & 135 & 43 & 104 & 2 & 4 \\
\hline 59 & Acc-241295 & 58 & 141 & 44 & 113 & 3 & 4 \\
\hline 60 & Acc-202318 & 61 & 140 & 50 & 107 & 4 & 4 \\
\hline 61 & Acc-241302 & 67 & 132 & 49 & 116 & 3 & 4 \\
\hline 62 & Acc-202370 & 58 & 131 & 51 & 96 & 3 & 3 \\
\hline 63 & Acc-202360 & 64 & 126 & 47 & 88 & 2 & 3 \\
\hline \multirow[t]{3}{*}{64} & Acc-212632 & 65 & 133 & 48 & 97 & 4 & 5 \\
\hline & Mean & 60.48 & 133.07 & 46.47 & 104.36 & 2.49 & 3.18 \\
\hline & SD (5\%) & 2.35 & 3.01 & 2.44 & 2.29 & 0.84 & 1.18 \\
\hline
\end{tabular}

DF = Days to $50 \%$ flowering, DM = Days to $90 \%$ maturity, CFP = Capsule filling period,

$\mathrm{PH}=$ Plant height $(\mathrm{cm}), \mathrm{PB}$, Number of primary branches per plant, $\mathrm{BPP}=$ Number of branches per plant 
Table 4: Mean values for yield components in 64 sesame populations

\begin{tabular}{|c|c|c|c|c|c|c|}
\hline No. & Populations & CPP & TSW (g) & SY (kg ha $\left.{ }^{-1}\right)$ & BY (kg ha $\left.{ }^{-1}\right)$ & $\mathrm{HI}$ \\
\hline 1 & Acc- 249212 & 81 & 2.29 & 378.00 & 3012.50 & 0.13 \\
\hline 2 & Acc-202289 & 74 & 2.04 & 588.00 & 1990.63 & 0.30 \\
\hline 3 & Acc-202374 & 68 & 2.75 & 469.00 & 3003.13 & 0.16 \\
\hline 4 & Acc-202376 & 84 & 2.50 & 454.69 & 1615.63 & 0.28 \\
\hline 5 & Acc-241305 & 103 & 2.34 & 488.00 & 3046.88 & 0.16 \\
\hline 6 & Acc-202356 & 83 & 2.07 & 445.94 & 3078.13 & 0.19 \\
\hline 7 & Acc- 241320 & 87 & 2.31 & 563.00 & 2993.75 & 0.19 \\
\hline 8 & Acc-202309 & 97 & 2.78 & 603.13 & 3046.88 & 0.20 \\
\hline 9 & Acc-241301 & 91 & 2.06 & 472.00 & 1618.75 & 0.29 \\
\hline 10 & Acc-202308 & 107 & 2.22 & 478.13 & 1562.50 & 0.31 \\
\hline 11 & Acc-241304 & 98 & 2.19 & 481.00 & 3029.13 & 0.16 \\
\hline 12 & Acc-202312 & 90 & 2.88 & 753.13 & 2971.88 & 0.25 \\
\hline 13 & Acc-202335 & 105 & 2.25 & 497.00 & 2025.00 & 0.25 \\
\hline 14 & Acc-202353 & 101 & 2.13 & 518.75 & 1987.50 & 0.26 \\
\hline 15 & Acc-241300 & 98 & 2.23 & 491.00 & 3096.88 & 0.16 \\
\hline 16 & Acc-228816 & 110 & 2.44 & 446.88 & 3756.25 & 0.12 \\
\hline 17 & Acc-202287 & 95 & 2.43 & 628.00 & 3068.75 & 0.20 \\
\hline 18 & Acc-241328 & 86 & 2.65 & 443.75 & 3059.38 & 0.15 \\
\hline 19 & Acc-211921 & 91 & 2.45 & 384.00 & 3018.75 & 0.13 \\
\hline 20 & Acc-202339 & 87 & 2.56 & 615.63 & 3012.50 & 0.20 \\
\hline 21 & Acc-202329 & 69 & 2.34 & 463.00 & 1603.13 & 0.29 \\
\hline 22 & Acc-202315 & 77 & 2.75 & 675.00 & 3771.88 & 0.18 \\
\hline 23 & Acc-203099 & 88 & 2.05 & 473.00 & 1953.13 & 0.24 \\
\hline 24 & Acc-202320 & 77 & 2.54 & 581.25 & 1984.38 & 0.29 \\
\hline 25 & Acc-212995 & 69 & 2.45 & 503.00 & 3028.13 & 0.17 \\
\hline 26 & Acc-202345 & 74 & 2.18 & 509.38 & 3800.00 & 0.13 \\
\hline 27 & Acc-9242 & 99 & 2.41 & 550.00 & 3075.00 & 0.18 \\
\hline 28 & Acc-241294 & 100 & 2.30 & 566.88 & 3053.13 & 0.19 \\
\hline 29 & Acc-202330 & 103 & 2.01 & 380.00 & 2021.88 & 0.19 \\
\hline 30 & Acc-241297 & 84 & 2.45 & 510.94 & 3050.00 & 0.17 \\
\hline 31 & Acc-212633 & 96 & 2.56 & 388.00 & 753.13 & 0.10 \\
\hline 32 & Acc-215816 & 104 & 2.99 & 901.56 & 3784.38 & 0.24 \\
\hline 33 & Acc-216896 & 116 & 2.57 & 470.00 & 121.88 & 0.15 \\
\hline 34 & Acc-202323 & 101 & 2.01 & 550.00 & 2000.00 & 0.28 \\
\hline 35 & Acc- 202313 & 98 & 2.43 & 595.00 & 3068.75 & 0.19 \\
\hline 36 & Acc-241298 & 79 & 2.78 & 746.88 & 3118.75 & 0.24 \\
\hline 37 & Acc-202332 & 89 & 2.10 & 516.00 & 2021.88 & 0.26 \\
\hline 38 & Acc-202288 & 84 & 2.43 & 596.88 & 3818.75 & 0.16 \\
\hline 39 & Acc-241296 & 79 & 2.01 & 456.00 & 2003.13 & 0.23 \\
\hline 40 & Acc-202511 & 101 & 2.45 & 553.13 & 3103.13 & 0.18 \\
\hline 41 & Acc-202343 & 104 & 2.31 & 570.00 & 3056.25 & 0.19 \\
\hline 42 & Acc-241293 & 106 & 2.51 & 506.25 & 3771.88 & 0.13 \\
\hline 43 & Acc-241347 & 98 & 2.45 & 488.00 & 3096.88 & 0.16 \\
\hline 44 & Acc-203104 & 92 & 2.06 & 440.63 & 2009.38 & 0.22 \\
\hline 45 & Acc-241299 & 88 & 2.34 & 403.00 & 3050.00 & 0.13 \\
\hline 46 & Acc-202327 & 86 & 2.40 & 500.00 & 3768.75 & 0.13 \\
\hline 47 & Acc-241291 & 94 & 2.79 & 544.00 & 3821.88 & 0.14 \\
\hline 48 & Acc-241314 & 83 & 2.01 & 368.75 & 2025.00 & 0.18 \\
\hline 49 & Acc-235405 & 92 & 2.45 & 406.00 & 3103.13 & 0.13 \\
\hline 50 & Acc-202364 & 101 & 2.65 & 503.13 & 3753.13 & 0.13 \\
\hline 51 & Acc-202306 & 88 & 2.41 & 459.00 & 3065.63 & 0.15 \\
\hline 52 & Acc-241303 & 94 & 2.31 & 525.88 & 3037.50 & 0.17 \\
\hline 53 & Acc-202286 & 96 & 2.11 & 403.00 & 3003.13 & 0.19 \\
\hline 54 & Acc-212994 & 84 & 2.30 & 540.66 & 3043.75 & 0.18 \\
\hline 55 & Acc-202317 & 91 & 2.01 & 334.00 & 2025.88 & 0.17 \\
\hline 56 & Acc-202286 & 87 & 2.60 & 396.88 & 3768.75 & 0.11 \\
\hline 57 & Acc-241329 & 89 & 2.55 & 463.00 & 3121.88 & 0.15 \\
\hline 58 & Acc-202373 & 96 & 2.66 & 596.88 & 3771.88 & 0.16 \\
\hline 59 & Acc-241295 & 101 & 2.74 & 553.00 & 3787.50 & 0.15 \\
\hline 60 & Acc-202318 & 89 & 2.12 & 456.25 & 3812.50 & 0.12 \\
\hline 61 & Acc-241302 & 99 & 2.44 & 534.00 & 3821.88 & 0.14 \\
\hline 62 & Acc-202370 & 90 & 2.32 & 503.13 & 3915.63 & 0.13 \\
\hline 63 & Acc-202360 & 74 & 2.11 & 525.00 & 3027.88 & 0.17 \\
\hline \multirow{3}{*}{64} & Acc-212632 & 80 & 2.41 & 459.38 & 3075.00 & 0.15 \\
\hline & Mean & 90.66 & 2.40 & 510.75 & 2991.34 & 0.18 \\
\hline & D (5\%) & 5.40 & 0.20 & 8.22 & 438.07 & 0.04 \\
\hline
\end{tabular}

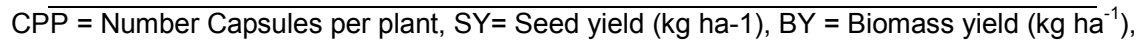
TSW $=1000$ seed weight $(\mathrm{g}), \mathrm{HI}=$ Harvest index, LSD= Least Significant Difference. 
Table 5: Estimates of genetic components of variance, heritability and genetic advance for different traits in sesame populations

\begin{tabular}{lcccccccc}
\hline T r a i t s & $\boldsymbol{\sigma}^{\mathbf{2}} \mathbf{g}$ & $\boldsymbol{\sigma}^{\mathbf{2}} \mathbf{p}$ & $\boldsymbol{\sigma}^{\mathbf{2}} \mathbf{c}$ & $\mathbf{G C V}(\%)$ & $\mathbf{P C V}(\%)$ & $\mathbf{h}^{\mathbf{2}} \mathbf{( \% )}$ & $\mathbf{G A}$ & $\mathbf{G A M}(\%)$ \\
\hline DF & 25.95 & 27.32 & 1.37 & 8.42 & 8.64 & 94.99 & 10.23 & 16.91 \\
DM & 45.67 & 47.91 & 2.24 & 6.48 & 6.63 & 95.32 & 13.59 & 13.02 \\
CFP & 13.17 & 14.62 & 1.45 & 7.81 & 8.23 & 90.08 & 7.10 & 15.27 \\
PH & 66.82 & 69.61 & 2.79 & 6.14 & 6.27 & 95.99 & 16.50 & 12.40 \\
NPB & 1.62 & 1.78 & 0.16 & 51.12 & 53.58 & 91.01 & 2.50 & 99.95 \\
BPP & 2.13 & 2.46 & 0.33 & 45.89 & 49.32 & 86.59 & 2.80 & 87.97 \\
CPP & 88.60 & 95.79 & 7.19 & 10.38 & 10.80 & 92.49 & 18.65 & 20.57 \\
SY & 8733.83 & 8750.09 & 16.26 & 18.30 & 18.31 & 99.81 & 192.34 & 37.66 \\
TSW & 0.03 & 0.07 & 0.04 & 7.57 & 11.26 & 45.21 & 0.25 & 10.48 \\
BY & 376557.20 & 428317.84 & 51760.64 & 20.52 & 21.88 & 87.92 & 1185.26 & 39.63 \\
HI & 0.0024 & 0.0028 & 0.0004 & 27.22 & 29.40 & 85.71 & 0.09 & 51.91 \\
\hline
\end{tabular}

$\mathrm{DF}=$ Days to $50 \%$ flowering, $\mathrm{DM}=$ Days to $90 \%$ maturity, CFP $=$ Capsule filling period, $\mathrm{PH}=$ Plant height $(\mathrm{cm}), \mathrm{NBP}=\mathrm{Number}$ of primary branches per plant; BPP $=$ Number of branches per plant, $\mathrm{CPP}=$ Number Capsules per plant, $\mathrm{SY}=\mathrm{Seed}$ yield $\left(\mathrm{kg}\right.$ ha $\left.{ }^{-1}\right), \mathrm{BY}=$ Biomass yield $\left(\mathrm{kg} \mathrm{ha}^{-1}\right)$, phenotypic $\left(\sigma^{2} \mathrm{p}\right)$, genotypic $\left(\sigma^{2} \mathrm{~g}\right)$ and environmental $\left(\sigma^{2} \mathrm{e}\right)$ components of variances, phenotypic (PCV) and genotypic (GCV) coefficients of variation, broad sense heritability $\left(\mathrm{h}^{2}\right)$, expected genetic advance $(\mathrm{GA})$ and genetic advance as percent of the mean (GAM).

Heritability in broad sense was greater than $80 \%$ for all traits except TSW (45.13\%). Estimates of genetic advance as percent of the mean (GAM) were greater than $30 \%$ for PB, BPP, SY, BY and HI. Desawi et al. (2014) also reported relatively higher estimates of heritability for DF, DM and CFP and higher estimates of GAM for CPP, NPB, TSW and SY. According to Singh (2001), heritability values greater than $80 \%$ are very high, values from 60 to $80 \%$ are high and values from 40 to $59 \%$ are medium and values less than $40 \%$ are low. High heritability value was reported by Sumathi and Muralidharan (2010) for days to maturity. High value of heritability indicates that there would be a close correspondence between the genotype and the phenotype due to the relative small contribution of the environment to the phenotype. But, for characters with low heritability, say $40 \%$ or less, selection may be considerably difficult or virtually impractical due to the masking effect of the environment. Considering this benchmark, heritability estimate was high $(>80 \%)$ for the majority of studied characters in the present investigation. Dabholkar (1992) explained that whenever values are stated for heritability of a character, it refers to a particular population under particular environmental conditions.

High heritability values coupled with high genetic advance as percent of mean was observed for SY, NPB, $\mathrm{BP}, \mathrm{BY}$, and $\mathrm{HI}$. This indicates the lesser influence of environment in expression of these characters and prevalence of additive gene action in their inheritance. Hence, they are amenable for simple selection. Similar findings were reported by Reddy et al. (2001) and Krishnaiah et al. (2002). According to Johnson et al. (1955), high heritability estimates along with the high genetic advance is usually more helpful in predicting gain under selection than heritability estimates alone. Genetic advance under selection (GA) refers to improvement of characters in genotypic value for the new population compared with the base population under one cycle of selection at a given selection intensity (Singh, 2001). This study showed higher heritability values but low genetic advance and genetic advance as percent of mean for $\mathrm{PH}$, DF, DM, CFP, and CPP, which was inconsistent with high heritability and high genetic advance for $\mathrm{PH}$ as reported by Govidarasu et al. (1990). In this study thousand seed weight showed low heritability and genetic advance as percent of the mean. Rajaravindran et al. (2000) and Paramasivam (1980) reported that high heritability and genetic advance for the seed yield per hectare, plant height and days to maturity in sesame populations. Emphasis should be placed on those characters which had high heritability and genetic advance for formulating reliable selection indices for the development of high yielding sesame varieties.

\section{CONCLUSION}

Sesame (Sesamum indicum L.) is an important crop produced in Ethiopia for oilseed production and it ranks first in total production from oil crops. A study was conducted to determine the extent of genetic variability, heritability and genetic advance among 64 sesame populations from Ethiopia. The results for analysis of variance showed that there were highly significant differences among the 64 populations for all characters considered. High values for GCV and PCV were observed in the populations for NPB, BPP, SY, BY and HI which could indicate the populations are variable and could be used for breeding stock. High to very high estimates for heritability values were observed for all traits except TSW which indicated that selection based on the phenotypes for specific objectives/traits are effective. And it further indicates the limited influence of the environment on the phenotypic expressions of the traits. Further computation for GAM indicated that high estimates were found for NPB, BPP, BY, SY and HI which could further confirm the easy of selections based on phenotypes after cycle of selection using $5 \%$ selection intensity. This study generally indicated that there were significance phenotypic variations among the populations. Thus, there is enormous opportunity of using the germplasm in the improvement program for employing different breeding techniques for selection of varieties with significant increase in economic trait like seed yield.

\section{Acknowledgments}

The authors are grateful to the Institute of Biodiversity Conservation of Ethiopia (IBC/E) for providing the seeds.

\section{Conflict of Interest}

The authors declared no conflict of interest. 


\section{Gadisa Hika et al.,}

\section{REFERENCES}

Alemu, A., Petros, Y., Tesfaye, K. (2013). Genetic distance of sesame (Sesamum indicum L.) cultivars and varieties from Northwestern Ethiopia using Inter Simple Sequence Repeat Markers. East African Journal of Sciences 7: 3140.

Allard, R.W. (1960). Principles of Plant Breeding. John Willey and Sons, New York.485p.

Bedigian, D., Harlan, R. (1986). Evidence for the cultivation of sesame in the ancient world. Economic Botany 40:137154

Brar, G.S., Ahuja, K.L. (1979). Sesame: its culture, genetics, breeding and biochemistry. PP. 245-313. In: Malik, C.P (Ed.), Annual Review of Plant Science, Kalyani publishers, New Delhi.

Burton, G.W., de Vane, E.H. (1953). Estimating heritability in Tall Fescue (Festuca arundinacea) from replicated clonal material. Agronomy Journal 45: 481-487.

CSA (Central Statistical Authority) (2014). Central Statistical Agency. Agricultural Sample Survey in 2013/2014 (2006 E.C.). Report on Area and Production of major crops for Private Peasant Holdings, Meher Season. Vol. 1, Statistical Bulletin Number 532, Addis Ababa, Ethiopia.

Dabholkar, A.R. (1992). Elements of Biometrical Genetics. Concept publishing Company .New Dehli, 431p.

Deressa, A. (2013). Evaluation of Soil Acidity in Agricultural Soils of Smallholder Farmers in South Western Ethiopia. Sci. Technology and Arts Research Journal 2(2): 01-06.

Desawi, H.T., Sentayehu, A.K., Daniel, E.G. (2014). Assessment of genetic variability, genetic advance, correlation and path coefficient analysis for morphological traits in sesame populations. Asian Journal of Agricultural Research 8(4): 181-194.

Deshmukh, S.N., Basu, M.S., Reddy, P.S. (1986). Genetic variability, character association and path coefficient analysis of quantitative traits in Viginia bunch varieties of ground nut. Indian Journal of Agricultural Science 56:515518

Endale, D., Parzies, H.K. (2011). Genetic variability among landraces of sesame in Ethiopia. African Crop Science Journal 19:1-13.

Gangarde, S.A., Bangar, N.D., Katore, T.D. (2009). Variability, heritability and genetic advance in sesame (Sesamum indicum L.). Journal of Mharashtra Agricultural University 34(2): 147-148.

Gidey, Y.T., Kebede, S.A., Gashawbeza, G.T. (2012). Extent and pattern of genetic diversity for morpho-agronomic traits in Ethiopian sesame landraces (Sesamum indicum L.). Asian Journal of Agricultural Research 6(3): 118-128.

Gomez, K.A., Gomez, A. A. (1984). Statistical Procedure for Agricultural Research, $2^{\text {nd }}$ Ed., John Wiley and Sons., Inc., USA, 680 pp.
Sci. Technol. Arts Res. J., Jan-March 2015, 4(1): 20-26

Gooding, M.J., Murdoch, A.J., Ellis, R.H. (2000). The value of seeds. pp.1-41. In: Black, M., Bewley, J.D. (Eds.), Seed Technology and Its Biological Basis. Sheffield Academic Press.

Govidarasu, R., Rathinam, M., Sivasubramania, P. (1990). Genetic variability in sesamum (Sesamum indicum L.). Madras Agricultural Journal 78(1-3): 450-452.

Gulhan, E., Melih, T., Kenan, T. (2004). Analysis of genetic diversity in Turkish sesame (Sesamum indicum L.) populations using RAPD markers. Genetic Resources and Crop Evolution 51: 599-607.

Hika, G., Geleta, N., Jaleta, Z. (2014). Correlation and divergence analysis for phenotypic traits in sesame (Sesamum indicum L.) populations. Science, Technology Arts Research Journal 3: 01-09.

IPGRI, NBPGR (2004). International Plant genetic Resources Institute, Rome, Italy and National Bureau of Indian Plant Genetic Resources, New Delhi, India, 61 pp.

Johnson, H.W., Robinson, H.F., Comstock, R.E. (1955). Estimates of genetic and environmental variability in soybeans. Agronomy Journal 47: 314-318.

Krishnaiah, G., Reddy, K.R. and Sekhar, M.R. (2002). Variability studies in Sesame. Crop Research 24: 501504.

Paramasivam, K. (1980). Genetic analysis of yield and yield components in $\mathrm{F} 2$ and $\mathrm{F} 3$ generations of sesame (Sesamum indicum L.). MSc., (Ag).Thesis. Tamil Nadu Agric.Univ., Coimbatore.

Rajaravindran,G., Kingshlin, M., Shunmagavalli, N. (2000). Heritability and genetic advance in sesame (Sesamum indicum L.). Sesame and Safflower News Letter 15:70-74.

Reddy, P.A.V., Sekhar, M.R., Rangnatha, A.R.G., Dhanraj, A. (2001). Genetic variability and heritability for seed yield and its components in Sesame. Journal of Oilseeds Research 18:173-175.

Salunkhe, D.K. and Desai, B.B. (1986). Post-Harvest biotechnology of oilseeds. CRC Press, Boca Raton, Florida. p. 105-117.

SAS (Statistical Analysis System). (2002).Version 9.0, USA.

Singh, B.D. (2001). Plant breeding: Principles and methods. Kalyani publishers, New Delhi. 896p.

Terefe, G., Wakjira, A., Berhe, M., Tadesse, H. (2012). Sesame Production Manual. EIAR/Embassy of the Kingdom of Netherlands, Ethiopia, 49p.

Wijnands, J., Biersteker, J., Hiel, R. (2007). Oilseeds Business Opportunities in Ethiopia. The Hague, 30 pp.

Yermanos, D. M., Hemstreet, S., Saeeb, W., Huszar, C.K. (1972). Oil content and composition of the seed in the world collection of sesame introductions. Journal of American Oil Chemistry Society 49:20-23. 